\title{
Validitas Perangkat Pembelajaran Fisika Dengan Model Post Organizer Berbantuan Video
}

\author{
Sukma Fatiah*, Ahmad Harjono, I Wayan Gunada \\ Program Studi Pendidikan Fisika, Universitas Mataram \\ *Email: sukmafatiyah98@gmail.com
}

Received: 10 Desember 2020;

Accepted: 19 Juni 2021;

Published: 20 Juni 2021

DOI: http://dx.doi.org/10.29303/jpft.v7i1.2268

\begin{abstract}
The purpose of this study is to determine the validity of the physics learning devices with post organizer models assisted by videos. The research design used research and development $(R \& D)$ design with 4D model (define, design, develop, \& disseminate). Learning tools developed are sylabus, lesson plan, learner worksheets, understanding of concept, and learning video. This paper only focused on the process of testing the validation of the contents and constructs of the learning tool. This study is restricted to limited testing by taking the results of validation from the validator and questionnaire of response from students. Validation results using CVR and CVI indicate learning tools in the very feasible categories and reliable. The results of limited trial show that students' response of $99.94 \%$ and $98.31 \%$ with very good categories. So it can be concluded that tools with post organizer models assisted by learning videos are feasible and can be used in physics learning.
\end{abstract}

Keywords: Learning Tools; Post Organizer Model; Learning Video

\section{PENDAHULUAN}

Pengetahuan alam atau lebih dikenal dengan ilmu sains mengkaji tentang segala fenomena yang terjadi di alam berdasarkan fakta-fakta empiris, yaitu fakta yang langsung dialami manusia dengan panca indera. Salah satu ilmu yang termasuk ke dalam ilmu sains adalah fisika. Budiyanto (2008) menyebutkan bahwa fisika adalah salah satu cabang IPA yang mendasari perkembangan teknologi maju dan konsep hidup harmonis dengan alam. Penguasaan konsep dalam pembelajaran fisika sangat penting.

Penanaman konsep yang baik melalui proses pembelajaran akan menciptakan produk yang berkualitas. Pembelajaran fisika tidak hanya menekankan pada aspek produk saja, tetapi juga tetap memperhatikan aspek proses dan sikap. Namun, fakta di lapangan menunjukkan bahwa pembelajaran sebagian besar hanya menekankan pada aspek produk saja, sehingga peserta didik cenderung lebih banyak menghafal rumus dan teori, bukan berdasarkan pemahaman.
Menurut Dahar (2011), dalam menerima informasi ada kemungkinan lebih cenderung menghafalkan informasi yang didapatkan tanpa mencoba mengaitkan dengan konsep yang pernah dimiliki sebelumnya.

Pemberian informasi yang kurang bermakna sulit diterima, sehingga akan mengurangi keaktifan di dalam kelas. Dahar (2011) mengatakan bahwa proses pembelajaran akan bermakna, jika dapat mengaitkan informasi baru pada konsepkonsep yang relevan yang terdapat di dalam struktur kognitif. Pernyataan ini diperkuat oleh Harjono et al, (2018) yang mengungkapkan bahwa pembelajaran bermakna didapatkan dengan mengaitkan konsep lama dan konsep baru.

Pembelajaran bermakna mendasari pembentukan integrasi konstruktif dari suatu pemikiran, perasaan, dan tindakan yang mengarah pada pemberdayaan untuk komitmen dan tanggung jawab. Hal ini sesuai dengan pernyataan Ausubel et al., (1968) bahwa pembelajaran bermakna dapat membangun tanggung jawab dan komitmen 
dalam diri peserta didik, sehingga mampu memahami makna dan tujuan dari suatu kegiatan pembelajaran yang dilakukan.

Salah satu upaya yang dilakukan untuk menumbuhkan pembelajaran bermakna, sehingga dapat mengasah penguasaan konsep adalah dengan model Post Organizer (PO). Model pembelajaran PO diterapkan di akhir pembelajaran yang lebih menekankan pada penguatan daya ingat terhadap materi yang telah dipelajari. Oktaviani et al, (2018) menyatakan bahwa PO yang mempunyai kemampuan untuk mengingat kembali sangat bermanfaat untuk menanamkan belajar menerima yang bermakna, dimana materi pelajaran yang tersusun disampaikan dari awal sampai akhir ke peserta didik, kemudian pengetahuan baru tersebut dikaitkan dengan pengetahuan yang sudah dimiliki.

Penggunaan model PO bukan hanya sebagai jembatan penghubung antara pengetahuan baru dengan sebelumnya, tetapi juga sebagai penguat memori terhadap materi yang baru saja dipelajari sehingga informasi yang didapatkan tertanam dengan baik dalam struktur kognitif. Hasil penelitian Oktaviani et al, (2018) membuktikan bahwa penggunaan $\mathrm{PO}$ dalam pembelajaran dapat meningkatkan penguasaan konsep fisika. PO mengarahkan peserta didik untuk dapat menyimpulkan materi pembelajaran dan membantu meningkatkan kemampuan daya ingat. Chung dan Cheon (2010) juga menyatakan bahwa penggunaan PO tidak hanya menghasilkan kemampuan daya ingat yang tinggi, tetapi juga persepsi positif terhadap suatu permainan.

Keberhasilan suatu pembelajaran didukung juga oleh penggunaan media yang tepat, salah satunya video. Resta (2013) menyatakan bahwa video pembelajaran dapat membuat belajar fisika lebih menarik, interaktif, dan komunikasi yang lebih menekankan pada proses pembentukan pengetahuan secara aktif, serta mampu mempertahankan konsentrasi peserta didik selama proses belajar. Berdasarkan hasil penelitian Suranti et al, (2016) mengungkapkan bahwa perpaduan model dan media pembelajaran yang sesuai dapat meningkatkan penguasaan konsep fisika peserta didik.

Oleh karena itu telah dikembangkan suatu perangkat pembelajaran dengan menggunakan model PO berbantuan video. Produk yang dihasilkan diantaranya adalah perangkat pembelajaran dengan model PO berbantuan video berupa silabus, RPP, LKPD, instrumen tes penguasaan konsep, dan video pembelajaran. Prosedur pengembangan mengikuti langkah-langkah pengembangan model 4-D yang memiliki susunan sistematis yaitu define, design, develop, disseminate dan setiap tahapannya sesuai dengan kegiatan penelitian dan pengembangan yang peneliti butuhkan. Selain itu, pada model 4-D juga terdapat tahap develop dengan validasi pakar atau ahli, sehingga produk yang dikembangkan lebih valid dan layak untuk digunakan dalam pembelajaran.

Sehingga, perangkat pembelajaran yang dikembangkan tersebut perlu dilakukan validitas. Hal ini sejalan dengan pendapat Putra et al, (2018) bahwa perlu dilakukan validitas pada perangkat pembelajaran untuk menjamin kualitasnya. Nugroho \& Ruwanto (2017) menambahkan bahwa validitas merupakan tahapan penilaian produk yang dihasilkan dari tahap perancangan oleh validator ahli dan praktisi berdasarkan perhitungan validitas isi. Pernyataan inilah yang mendasari penelitian ini dengan tujuan untuk mengetahui kelayakan perangkat pembelajaran fisika yang dikembangkan dengan model PO berbantuan video. 


\section{METODE PENELITIAN}

Penelitian ini merupakan penelitian pengembangan dengan menggunakan model 4-D yang terdiri dari tahap pendefinisian (define), perancangan (design), pengembangan (develop) dan penyebaran (disseminate) (Thiagarajan et al, 1974). Penelitian ini hanya dibatasi sampai pada tahap uji coba terbatas. Perangkat pembelajaran yang dikembangkan, yaitu silabus, Rencana Pelaksanaan Pembelajaran (RPP), Lembar Kerja Peserta Didik (LKPD), instrumen tes penguasaan konsep, dan video pembelajaran.

Pengembangan

perangkat pembelajaran dimulai dengan tahap pendefinisian untuk mendefinisikan syaratsyarat dan kebutuhan-kebutuhan dalam pembelajaran yang meliputi analisis awal, analisis peserta didik, analisis tugas, dan analisis konsep. Tahap selanjutnya adalah tahap perancangan format perangkat pembelajaran seperti penyusunan instrumen penelitian, pemilihan media, pemilihan format, dan melakukan rancangan awal perangkat pembelajaran. Hasil rancangan awal perangkat pembelajaran dilakukan uji validitas dan uji kepraktisan dengan melakukan uji coba terbatas kepada mahasiswa Program Studi Pendidikan Fisika Universitas Mataram dan peserta didik kelas XI dan XII.

Uji kevalidan perangkat pembelajaran dilakukan oleh tiga validator ahli dan tiga validator praktisi dengan cara mengisi lembar validasi. Data validasi diperoleh dengan perhitungan CVR dan CVI. Cara menghitung nilai CVR menurut Lawshe (1975) adalah menggunakan persamaan sebagai berikut:

$$
\mathrm{CVR}=\frac{\mathrm{Ne}-\frac{\mathrm{N}}{2}}{\frac{\mathrm{N}}{2}}
$$

Keterangan:
$\mathrm{Ne}$ : jumlah validator yang setuju (dianggap setuju/layak jika nilai setiap aspek dari kisaran 3-4, jika <3 dianggap tidak setuju/tidak layak)

$\mathrm{N}$ : jumlah total validator

Selanjutnya, dihitung CVI yang merupakan indikasi validitas isi tes yaitu rata-rata nilai CVR dari semua item. Rumus dari CVI dapat dilihat pada Persamaan 2.

$$
\mathrm{CVI}=\frac{\text { jumlah seluruh CVR }}{\text { jumlah butir item }}
$$

Kategori hasil perhitungan CVR dan CVI menurut Lawshe (1975) adalah dengan rentang $-1<x<1$. Angka tersebut dikategorikan dengan kriteria: $0<x<1=$ sangat layak; $0=$ layak; dan $-1<x<0=$ tidak layak.

Reliabilitas dalam penelitian ini menggunakan metode Borich yang dikenal dengan Percentage Agreement (PA) yaitu persentase kesepakatan antar penilai yang merupakan suatu prosentase kesesuaian nilai antara penilai pertama dengan penilai kedua. Perangkat dikatakan reliabel jika nilai persentase kesepakatan lebih atau sama dengan $75 \%$. Jika dihasilkan kurang dari $75 \%$, maka harus diuji untuk kejelasan dan persetujuan dari pengamat (Borich, 1994). Percentage Agreement (PA) dapat dirumuskan sesuai dengan Persamaan 3.

$$
P A=\left(1-\frac{A-B}{A+B}\right) 100 \%
$$

Keterangan:

A : skor penilai yang lebih besar

B : skor penilai yang lebih kecil

Selanjutnya dilakukan uji coba terbatas sebagai penilaian kepraktisan dan keterbacaan perangkat ke mahasiswa dan peserta didik untuk mengetahui tingkat respon terhadap perangkat pembelajaran yang dikembangkan oleh peneliti. Peneliti menyebarkan angket ke 30 mahasiswa Program Studi Pendidikan Fisika dan 30 
peserta didik yang telah belajar materi momentum dan impuls yaitu kelas XI dan kelas XII melalui google form. Data respon mahasiswa dan peserta didik terhadap perangkat pembelajaran berupa angket respon dengan skala 1 sampai 4 dengan kriteria: $1=$ tidak setuju, $2=$ kurang setuju, $3=$ cukup setuju, dan $4=$ setuju. Skala 3 dan 4 menunjukkan respon positif dan skala 1 dan 2 menunjukkan respon negatif. Menurut Hobri (2010), Prosentase Respon (PR) dihitung dengan rumus:

$\mathrm{PR}=\frac{\text { banyak respon positif }}{\text { banyak responden }} \times 100 \%$
Kriteria hasil prosentase yang diperoleh meliputi: $81 \%-100 \%=$ sangat baik; $61 \%-80 \%=$ baik; $41 \%-60 \%=$ cukup baik; $21 \%-40 \%=$ kurang baik; dan $\leq$ $20 \%=$ sangat kurang baik (Riduwan, 2013)

\section{HASIL DAN PEMBAHASAN}

Karakteristik Perangkat dengan Model PO Berbantuan Video Pembelajaran

Desain awal perangkat pembelajaran yang dikembangkan dapat dilihat pada Tabel 1.

Tabel 1. Spesifikasi Model PO Berbantuan Video Pembelajaran

\begin{tabular}{|c|c|c|}
\hline No & Komponen & Uraian Isi \\
\hline 1. & Silabus & $\begin{array}{l}\text { Silabus ini sebagai dasar penyusunan RPP yang didalamnya berisi Kompetensi } \\
\text { Inti (KI), Kompetensi Dasar (KD), materi pokok, sintaks model PO berbantuan } \\
\text { video pembelajaran, bentuk penilaian yang digunakan, alokasi waktu, dan } \\
\text { sumber belajar. }\end{array}$ \\
\hline 2. & RPP & $\begin{array}{l}\text { Rumusan tujuan pembelajaran menunjukkan kecakapan abad } 21 \text { dengan } \\
\text { memenuhi indikator penguasaan konsep C1-C6. } \\
\text { Pemilihan metode dan media pembelajaran yang digunakan dapat mendukung } \\
\text { peningkatan penguasaan konsep fisika peserta didik. } \\
\text { Langkah pembelajaran sesuai dengan sintak model PO berbantuan video } \\
\text { pembelajaran, yaitu tahap persiapan (preparation), penyajian materi } \\
\text { (presentation), menghubungkan (correlation), menyimpulkan (generalization) } \\
\text { dengan penyajian PO berbantuan video, dan penerapan (application) dengan } \\
\text { pemberian LKPD. }\end{array}$ \\
\hline 3. & LKPD & $\begin{array}{l}\text { LKPD disusun dalam bentuk diskusi dan eksperimen untuk melengkapi } \\
\text { penerapan model PO berbantuan video pembelajaran dengan tujuan dapat } \\
\text { memudahkan menguasai konsep momentum dan impuls. }\end{array}$ \\
\hline 4. & $\begin{array}{l}\text { Instrumen Tes } \\
\text { Penguasaan } \\
\text { Konsep }\end{array}$ & $\begin{array}{l}\text { Soal pilihan ganda yang mengacu pada kemampuan kognitif C1-C6, yaitu } \\
\text { kemampuan mengingat, memahami, mengaplikasikan, menganalisis, } \\
\text { mengevaluasi, dan mencipta. }\end{array}$ \\
\hline 5. & $\begin{array}{l}\text { Video } \\
\text { Pembelajaran }\end{array}$ & $\begin{array}{l}\text { Diterapkan di akhir kegiatan inti pembelajaran untuk membantu menyimpulkan } \\
\text { dan memudahkan peserta didik menguasai konsep momentum dan impuls. } \\
\text { Pada bagian awal video, menyajikan tujuan pembelajaran yang dilanjutkan } \\
\text { dengan pemaparan konsep momentum dan impuls beserta aplikasinya dalam } \\
\text { kehidupan sehari-hari, bagian kedua menayangkan aplikasi hukum kekekalan } \\
\text { momentum pada roket air sederhana dan penjelasan prinsip kerja roket } \\
\text { berdasarkan hukum kekekalan momentum, dan bagian akhir video menayangkan } \\
\text { penjelasan mengenai jenis-jenis tumbukan yang disertai dengan simulasi virtual } \\
\text { tumbukan. }\end{array}$ \\
\hline
\end{tabular}


Perangkat pembelajaran yang dikembangkan dalam penelitian ini memiliki karakteristik dengan penggunaan sintak model PO berbantuan video pembelajaran. Penerapan model PO diharapkan mampu meningkatkan penguasaan konsep fisika peserta didik. PO dapat mengarahkan peserta didik untuk dapat menyimpulkan materi pembelajaran dan membantu meningkatkan kemampuan daya ingat. Pernyataan ini sejalan dengan hasil penelitian Butz et al, (2005) dan Chung \& Cheon (2010) bahwa PO membantu peserta didik mengembangkan skema pada dirinya, sehingga meningkatkan kemampuan daya ingat dan membantu dalam menyimpulkan kegiatan pembelajaran dengan mengingat kembali informasi sebelumnya.

Penerapan PO diprediksikan dapat menambah kebermaknaan dalam pembelajaran. Hal ini sesuai dengan temuan Rizqa et al, (2020) bahwa pemberian PO berperan dalam menghadirkan pembelajaran bermakna dan memperkuat struktur kognitif peserta didik, sehingga informasi yang diterima tahan lama. Diperkuat dengan pendapat Harjono, (2012) bahwa organizer dapat membantu agar informasi lebih bermakna (meaningful) dengan menghubungkan pengetahuan sebelumnya dengan pengetahuan baru.

PO pertama kali diperkenalkan oleh David Ausubel dengan tujuan mempertahankan metode ceramah. Pada pembelajaran, PO tidak memiliki sintak tersendiri dalam penerapannya, sehingga peniliti memadukan dengan model ekspositori yang sama-sama menggunakan metode ceramah. Menurut Arsa (2015), terdapat lima langkah dalam pelaksanaan pembelajaran menggunakan model ekspositori, yaitu: (a) persiapan (preparation), (b) penyajian (presentation), (c) menghubungkan (correlation), (d) menyimpulkan (generalization), dan (e) penerapan (application). Perpaduan model ekspositori dengan penyajian PO berbantuan video pada tahap menyimpulkan dapat membentuk pembelajaran bermakna. Peneliti menyimpulkan bahwa model pembelajaran PO adalah pengaplikasian model dengan metode ceramah yang diterapkan di akhir pembelajaran guna memperkuat dan mempertahankan konsep yang telah dipelajari agar tersimpan lebih lama dalam struktur kognitif peserta didik dengan sintak mulai dari tahap persiapan (preparation) sebelum kegiatan pembelajaran dimulai, penyajian materi (presentation), menghubungkan (correlation) materi momentum impuls dengan pengalaman peserta didik, menyimpulkan (generalization) dibantu dengan penyajian PO, dan penerapan (application) dengan pemberian LKPD.

Penerapan PO membantu agar konsep tertanam lebih kuat dalam struktur kognitif. Peterson (1971) mengemukakan bahwa PO dirancang untuk memfasilitasi ingatan atau penyimpanan dari materi yang baru disajikan dengan menunjukkan bagaimana materi baru yang telah dipelajari berkaitan dengan pengetahuan sebelumnya yang sudah dimiliki. Chung dan Cheon (2010) juga menyatakan bahwa penggunaan PO tidak hanya menghasilkan kemampuan daya ingat yang tinggi, tetapi juga persepsi positif terhadap suatu permainan.

Model PO dikombinasikan dengan video untuk mengembalikan konsentrasi peserta didik dan membantu menyimpulkan pembelajaran. Video diaplikasikan pada kegiatan menyimpulkan diakhir kegiatan inti pembelajaran untuk mempertahankan konsentrasi peserta didik. Menurut Resta, (2013), video pembelajaran dapat membuat belajar fisika lebih menarik, interaktif, dan komunikasi yang lebih menekankan pada proses pembentukan pengetahuan secara aktif, serta mampu mempertahankan 
konsentrasi peserta didik selama proses belajar. Handziko dan Suyanto (2015) menyatakan bahwa pengembangan suatu video pembelajaran dapat meningkatkan penguasaan konsep. Berdasarkan temuan Suranti et al, (2016) dan Suharsa et al, (2018) mengungkapkan bahwa perpaduan model dan media pembelajaran yang sesuai dapat meningkatkan penguasaan konsep fisika peserta didik. Hasil penelitian Rahmawati et al, (2016) membuktikan bahwa perangkat yang dikembangkan dengan suatu model berbantuan video sangat diapresiasi positif oleh peserta didik dan layak digunakan dalam pembelajaran.

\section{Hasil Validasi Perangkat}

Perangkat pembelajaran divalidasi oleh tiga validator ahli dari dosen pendidikan fisika dan tiga validator praktisi dari guru fisika untuk mengetahui tingkat kelayakan perangkat pembelajaran yang dikembangkan. Menurut Amir et al, (2015), perangkat pembelajaran yang valid dan layak adalah sekumpulan perlengkapan belajar yang memenuhi kriteria validitas isi berdasarkan penilaian para ahli/pakar. Nugroho \& Ruwanto (2017) menegaskan bahwa validasi merupakan tahapan penilaian produk yang dihasilkan dari tahap perancangan oleh validator ahli dan praktisi berdasarkan perhitungan validitas isi. Perhitungan validitas isi pada penelitian ini menggunakan CVR dan CVI. Hasil validasi perangkat pembelajaran dapat dilihat pada Tabel 2. Berdasarkan hasil validasi terlihat bahwa CVI setiap komponen perangkat pembelajaran masuk dalam kategori sangat layak dan reliabel. Hasil ini sesuai dengan penelitian Primadani et al, (2016) bahwa perangkat pembelajaran yang dikembangkan dengan kategori layak dapat digunakan dalam pembelajaran fisika.

Nilai CVI yang paling kecil diperoleh pada LKPD dikarenakan kualitas penyusunan masih kurang pada aspek isi yang disajikan, khususnya pada bagian langkah pengerjaan LKPD. Oleh karena itu, peneliti melakukan revisi untuk perbaikan melalui saran yang diberikan oleh validator, sehingga seluruh perangkat yang dikembangkan dapat dirancang dengan baik. Pengembangan LKPD yang dirancang dengan baik dapat meningkatkan partisipasi dan pemahaman peserta didik terhadap materi yang disampaikan (Afkar \& Hartono, 2017).

Tabel 2. Hasil Validasi dan Perhitungan Reliabilitas Perangkat Pembelajaran

\begin{tabular}{llcccc}
\hline \multirow{2}{*}{ No } & Perangkat & \multicolumn{3}{c}{ CVI } & \\
\cline { 2 - 4 } & & Validator & Validator & Reliabilitas & Kategori \\
\hline 1. & Silabus & 1 & 1 & 94,30 & Sangat Layak/Reliabel \\
2. & RPP & 0,96 & 1 & 95,33 & Sangat Layak/Reliabel \\
3. & LKPD & 0,66 & 1 & 92,62 & Sangat Layak/Reliabel \\
4. & Instrumen Tes & 0,85 & 1 & 94,41 & Sangat Layak/Reliabel \\
& Penguasaan Konsep & & & & \\
5. & Video Pembelajaran & 1 & 0,94 & 94,32 & Sangat Layak/Reliabel \\
\hline
\end{tabular}

Perangkat pembelajaran yang divalidasi telah mengalami revisi pada beberapa aspek sesuai dengan masukan dari validator, seperti pada aspek tulisan, yaitu menyederhanakan penggunaan kalimat dan merevisi penggunaan kata yang kurang tepat, aspek isi yaitu pada silabus harus ada kesesuaian kegiatan pembelajaran dengan Kompetensi Dasar (KD); menambah referensi sumber belajar; merevisi tujuan 
pembelajaran pada RPP yang harus disesuaikan dengan ABCD (audience, behavier, condition, \& degree) dan disesuaikan dengan $\mathrm{KD}$; memperjelas kegiatan guru dan peserta didik; menyesuaikan tujuan pembelajaran pada LKPD dengan RPP; menyesuaikan soal pada instrumen tes dengan tujuan pembelajaran, dan membatasi keluasan video. Pada aspek tampilan yaitu menambahkan NIM dan logo di awal video; menghilangkan gambar yang tidak perlu, mengganti animasi tumbukan di awal video; memperbaiki simbol $\mathrm{H}_{2} \mathrm{O}$ dan $\mathrm{O}_{2}$; memperbesar tulisan persamaan dan keterangannya, memperbesar volume suara. Sudiarman et al, (2015) dan Fatmawati
(2016) menyatakan bahwa penilaian dan saran dari validator dilakukan sebagai masukan dan dasar untuk merevisi perangkat pembelajaran, sehingga dapat digunakan pada uji kelompok kecil dan uji lapangan.

\section{Hasil Uji Coba Terbatas}

Uji coba terbatas dilakukan untuk mengetahui kepraktisan dan keterbacaan perangkat pembelajaran yang dikembangkan (Nisyah et al, 2019). Uji ini dilakukan oleh mahasiswa sebagai calon guru dan peserta didik karena keduanya adalah pengguna dari perangkat yang telah dibuat. Hasil uji coba terbatas melalui google form disajikan pada Gambar 1.

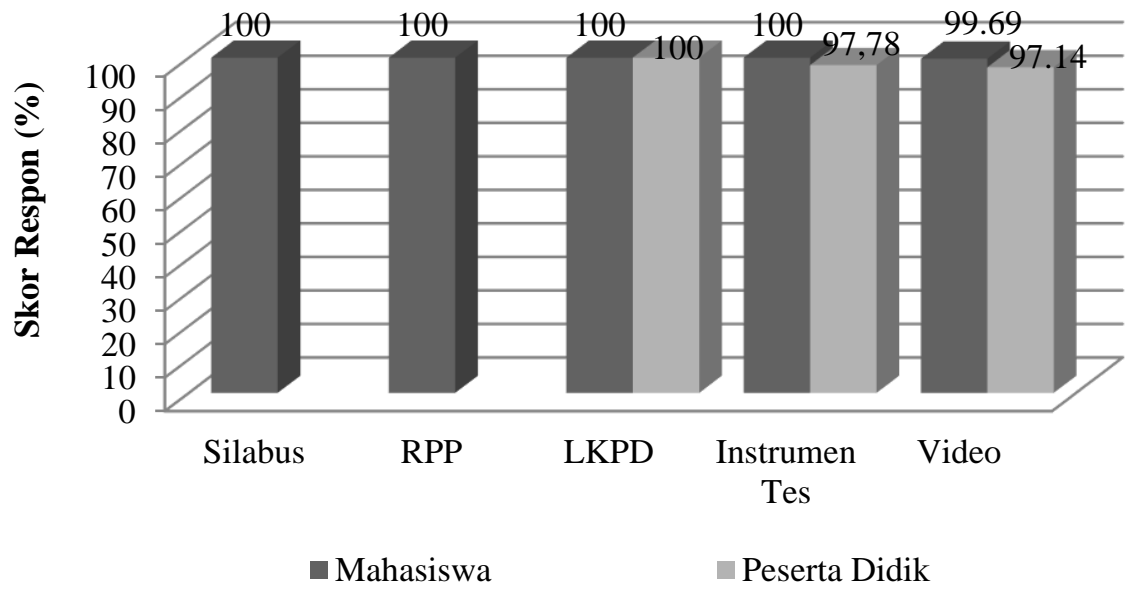

Gambar 1. Respon Mahasiswa dan Peserta Didik terhadap Perangkat dengan Model PO Berbantuan Video Pembelajaran

Gambar 1 menunjukkan bahwa respon mahasiswa dan peserta didik terhadap perangkat pembelajaran berkisar antara $81 \%-100 \%$ dengan kategori sangat baik yang berarti direspon positif. Respon positif menunjukkan bahwa mahasiswa dan peserta didik dapat menerima dengan baik perangkat pembelajaran yang dikembangkan dan tertarik apabila perangkat tersebut diterapkan dalam pembelajaran fisika (Sulardi et al, 2015). Dengan demikian, dapat disimpulkan bahwa perangkat pembelajaran dapat diterima dan difahami dengan baik oleh mahasiswa dan peserta didik.

Hasil uji coba terbatas ini juga dilengkapi dengan pemberian komentar dan saran oleh mahasiswa dan peserta didik. Saran digunakan sebagai dasar untuk menyempurnakan produk sebelum dilakukan uji coba luas untuk mengetahui efektivitas pembelajaran menggunakan perangkat yang dikembangkan (Nisyah et al, 2019). Komentar dan saran yang diberikan oleh mahasiswa dan peserta didik diantaranya, meninjau kembali indikator ke4 pada RPP karena terdapat penggunaan kata 
yang kurang tepat, merevisi tujuan pembelajaran, mempertimbangkan penggunaan waktu, meninjau kembali LKPD 3, merevisi kalimat di langkah kerja 1 yang menimbulkan makna ganda, volume suara pada video dibesarkan, dan menambahkan penjelasan konsep.

\section{PENUTUP}

Berdasarkan hasil validasi dan uji coba terbatas, maka dapat disimpulkan bahwa perangkat dengan model post organizer berbantuan video pembelajaran yang telah dikembangkan sangat layak digunakan dalam pembelajaran fisika. Tahap uji coba luas, yaitu ke sekolah dapat dilakukan untuk mengetahui efektivitas perangkat dengan model post organizer berbantuan video pembelajaran dalam meningkatkan penguasaan konsep fisika peserta didik.

\section{REFERENSI}

Afkar, F. I., \& Hartono, R. (2017). Pengembangan Lembar Kegiatan Peserta Didik dengan Model Pengembangan 4-D pada Materi Mitigasi Bencana dan Adaptasi Bencana Kelas X SMA. Jurnal Pendidikan Geografi. (2):135-147.

Amir, M., Muris, M., \& Arsyad, M. (2015). Pengembangan Perangkat Pembelajaran Berbasis Pengalaman pada Peserta Didik Kelas XI IPA SMA Negeri 9 Pinrang. Jurnal Sains dan Pendidikan Fisika. 11(3):202213.

Arsa, I. P. S. (2015). Belajar dan Pembelajaran Strategi Belajar yang Menyenangkan. Yogyakarta: Media Akademi.

Ausubel, D. P. (1968). Educational Psychology: A Cognitive View. New York: Holt, Rinehart, and Winston.

Borich, G. D. (1994). Observation Skills for Effective Teaching. New York: Merrill.
Budiyanto, J. (2008). Fisika untuk SMA/MA Kelas XII. Jakarta: Pusat Perbukuan Departemen Pendidikan Nasional.

Butz, J. A., Miller, S. P., \& Butz, C. (2005). Effect of Post-Organizer on Preservice Teacher's Content Knowledge and Understanding of Effective Teaching Behaviors. The Teacher Educator. 41(1):1-15.

Chung, S., \& Cheon, J. (2010). The Effect of Post Organizer in Game-Based Learning. Texas Tech University. 23(4):17-20.

Dahar, R. W. (2011). Teori-Teori Belajar dan Pembelajaran. Jakarta: Erlangga.

Fatmawati, A. (2016). Pengembangan Perangkat Pembelajaran Konsep Pencemaran Lingkungan Menggunakan Model Pembelajaran Berdasarkan Masalah untuk SMA Kelas X. Jurnal EduSains. 4(2):94103.

Gunawan, G. (2015). Model Pembelajaran Sains Berbasis ICT. Mataram: FKIP Universitas Mataram.

Harjono, A. (2012). Perbedaan Strategi Pembelajaran dan Pemberian Advance Organizer Pengaruhnya terhadap Hasil Belajar Fisika Siswa Kelas X. Jurnal Pijar MIPA. 7(1):13-17.

Harjono, A., Gunada, I. W., Sutrio, S., \& Hikmawati, H. (2018). Penerapan Advance Organizer dengan Model Pembelajaran Ekspositori Berpola Lesson Study untuk Meningkatkan Hasil Belajar Fisika Peserta Didik. Jurnal Pendidikan Fisika dan Teknologi. 4(1): 141-150.

Handziko, C. R., \& Suyanto, S. (2015). Pengembangan Video Pembelajaran Suksesi Ekosistem untuk Meningkatkan Motivasi Belajar dan Penguasaan Konsep Mahasiswa Biologi. Jurnal Inovasi Pendidikan IPA. 1(2): 212-224. 
Hobri, H. (2010). Metodologi Penelitian Pengembangan (Aplikasi pada Penelitian Pendidikan Matematika). Jember: Pena Salsabila.

Lawshe, C. H. (1975). A Quantitative Approach to Content Validity. Journal of Personnel Psychology: Purdue University. Pages: 563-575.

Nisyah, M., Gunawan, G., Harjono, A., \& Kusdiastuti, M. (2019). Perangkat Pembelajaran Model Inkuiri Dipadu Advance Organizer untuk Meningkatkan Penguasaan Konsep dan Kemampuan Pemecahan Masalah Fisika Siswa. Jurnal Pijar MIPA. xx(x): 1-6.

Nugroho, I. R., \& Ruwanto, B. (2017). Pengembangan Media Pembelajaran Fisika Berbasis Media Sosial Instagram sebagai Sumber Belajar Mandiri untuk Meningkatkan Motivasi dan Prestasi Belajar Fisika Siswa Kelas XI SMA. Jurnal Pendidikan Fisika. 6(6):460-470.

Oktaviani, D. G., Harjono, A., \& Gunada, I. W. (2018). Penguasaan Konsep Usaha dan Energi Peserta Didik Kelas X dengan Model Pembelajaran Ekspositori Berbantuan Organizers. Jurnal Pendidikan Fisika dan Teknologi.4(2): 192-201.

Peterson, J. C. (1971). Effect of an Advanced Organizer, A Post Organizer, or Knowledge of a Behavioral Objective on Achievement and Retention of a Mathematical Concept. Annual Meeting of the American Educational Research Association: $1-20$.

Primadani, R., Tukiran, T., \& Jatmiko, B. (2016). Pengembangan Perangkat Pembelajaran Fisika Model Structured Inquiry untuk Meningkatkan Keterampilan Pemecahan Masalah Siswa pada Materi Fluida Statis. Jurnal Penelitian Pendidikan Sains. 6(1):1235-1245.
Rahmawati, F., Soegimin, S., \& Kardi, S. (2016). Pengembangan Perangkat Pembelajaran Fisika Model Inkuiri Terbimbing Berbantuan Videoscribe pada Materi Kalor untuk Meningkatkan Hasil Belajar Siswa SMAN 1 Kedungwaru. Jurnal Penelitian Pendidikan Sains. 5(2):1039-1047.

Resta, L. I., Fauzi, A., \& Yulkifli, Y. (2013). Pengaruh Pendekatan Pictorial Riddle Jenis Video terhadap Hasil Belajar Siswa dalam Pembelajaran Inkuiri pada Materi Gelombang Terintegrasi Bencana Tsunami. Jurnal Pillar of Physics Education. 1(1): 17-22.

Riduwan, R. (2013). Skala Pengukuran Variabel-Variabel Penelitian. Bandung: Alfabeta.

Rizqa, A., Harjono, A., \& Wahyudi, W. (2020). Kemampuan Pemecahan Masalah Fisika Peserta Didik Melalui Model Pembelajaran Inkuiri Terbimbing Berbantuan Post Organizer. Jurnal Hasil Kajian, Inovasi, dan Aplikasi Pendidikan Fisika. 6(1):243-247.

Sudiarman, S., Soegimin, W. W., \& Susantini, E. (2015). Pengembangan Perangkat Pembelajaran Fisika Berbasis Inkuiri Terbimbing untuk Melatihkan Keterampilan Proses Sains dan Meningkatkan Hasil Belajar pada Topik Suhu dan Perubahannya. Jurnal Penelitian Pendidikan Sains. 4(2): 658-671.

Suharsa, U., Qaddafi, M., \& Baharuddin, B. (2018). Efektivitas Penerapan Model Pembelajaran Problem Based Learning Berbantuan Video Based Laboratory terhadap Peningkatan Pemahaman Konsep Fisika. Jurnal Pendidikan Fisika. 6(2): 57-64.

Sulardi, S., Nur, M., \& Widodo, W. (2015). Pengembangan Perangkat Pembelajaran Fisika Model Problem Based Learning (PBL) untuk Melatih Keterampilan Berpikir 
Kritis Siswa. Jurnal Penelitian

Pendidikan Sains. 5(1): 802-810.

Suranti, N. M. Y., Gunawan, G., \& Sahidu, H. (2016). Pengaruh Model Project Based Learning Berbantuan Media Virtual Terhadap Penguasaan Konsep Peserta Didik pada Materi Alat-Alat Optik. Jurnal Pendidikan Fisika dan Teknologi. 2(2): 73-79.

Thiagarajan, S., Semmel, D. S., \& Semmel, M. I. (1974). Instructional Development for Training Teachers of Expectional Children. Minneapolis, Minnesota: Leadership Training Institute/Special Education, University of Minnesota. 